\title{
La educación en tiempo de pandemia COVID 19: ¿realidad o ficción?
}

\author{
Education in a time of pandemic COVID 19: fact or fiction? \\ Educação em tempos de pandemia COVID 19: fato ou ficção?
}

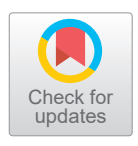

Como citar este artigo: Velásquez Vergara Sandra M., Ruidiaz Gómez Keydis S. La educación en tiempo de pandemia COVID 19: ¿realidad o ficción?. Revista Cuidarte. 2021;12(1):e1336. http://dx.doi.org/10.15649/cuidarte.1336

\section{Revista Cuidarte \\ Rev Cuid. Ene. - Abril. 2021; 12(1): e1336 \\ doi) http://dx.doi.org/10.15649/cuidarte.1336}

E-ISSN: 2346-3414

(1) Sandra M. Velásquez Vergara ${ }^{1}$

(1) Keydis S. Ruidiaz Gómez ${ }^{2}$

1 Universidad de Antioquia. Facultad de Ciencias Sociales y Humanas, Medellín-Colombia, E-mail: sandra.velasquez3@udea.edu. co.

2 Universidad del Sinú EBZCartagena, Escuela de Enfermería, Cartagena-Colombia, E-mail: coordinvestenfermeria@ unisinucartagena.edu.co

\section{Estimada editora,}

De manera sorpresiva el COVID-19 detuvo al mundo, o puntualmente frenó el acelerado ritmo en que confluía la actividad humana, pues los capullos siguen brotando en primavera, las ballenas continúan sus largas migraciones por el océano, la temporada de sequía volvió para quemar la tierra y el planeta continuó su incesante danza de rotación y traslación. Es decir, todos los seres vivos continuaron con normalidad su existencia, excepto los seres humanos, aterrados por una muerte invisible y un enemigo despiadado que hasta este momento parece infranqueable ${ }^{1}$.

Hoy, los seres humanos han detenido sus relaciones y modificado drásticamente sus vidas, encerrándose en unidades cada vez más pequeñas: el Estado-nación, la ciudad, el municipio, el barrio, la casa, la soledad, en fin ${ }^{1}$. De este modo, ante el confinamiento producto de la pandemia por COVID-19, la tecnología pasó a ser indispensable para el curso "normal" de la vida, lo que conllevó a una dependencia de los dispositivos electrónicos, trasladando de manera acelerada actividades como el trabajo, las clases, el deporte, las compras e incluso el contacto con los seres queridos para migrar a un espacio virtual totalmente ajeno para la gran mayoría de los individuos².

$Y$, aunque por un lado pareciese que la vida tal y como la conocíamos se detuvo, por otro lado, parece que no fue así, pues la recolección de basura, la producción textil, la venta de alimentos, la política, las diversas funciones del Estado, el periodismo, los delitos, la violencia patriarcal hacia las mujeres, las niñas y los niños, los hospitales y las instituciones educativas continúan activas, algunas modificadas, otras intactas. Así todo
Recibido: junio 26 de 2020

Aceptado: septiembre 10 de 2020

Publicado: noviembre 13 de 2020 $\nabla *$ Correspondencia

Keydis S. Ruidiaz Gómez

E-mail:coordinvestenfermeria@unisinucartagena.edu.co 
parece indicar que son necesarias para la supervivencia colectiva, por avaricia, por inercia o por una mezcla inexplicable de regulación social, historia y esperanza'.

En este último caso se encuentra la educación la cual migró de las aulas al encierro familiar, cumpliendo con funciones básicas como la regulación social, el uso del tiempo o la rutina diaria, el cumplimiento de responsabilidades académicas y laborales entre otros asuntos. Cabe resaltar que la situación actual producto de la pandemia por COVID-19 ha implicado y seguirá trayendo consigo múltiples cambios en los hogares, ya que el forzoso arribo de los asuntos escolares al seno de las dinámica familiar, dista de ser una situación ligera y serena, dado que ha generado diversos conflictos y discusiones sobre la inevitable colaboración entre ambas instituciones sociales (hogar y academia), así como el aporte de las instituciones educativas al desarrollo y formación de las comunidades en su conjunto ${ }^{3}$.

En un abrir y cerrar de ojos el sistema educativo se trasladó a un espacio virtual, llevando a los docentes, alumnos y familias a realizar un gran esfuerzo en tiempo récord. En este sentido, los primeros actores de este proceso tuvieron que adoptar y adaptar los contenidos y metodologías al confinamiento de su alumnado, los segundos responder a las demandas escolares y pretender que el sistema de enseñanza-aprendizaje que hoy se oferta, cumpla su función a distancia y logre formar a los ciudadanos del futuro de manera adecuada según sus necesidades ${ }^{4}$.

De este modo, con la "universidad instalada" en el núcleo del hogar, las actividades académicas y las jornadas laborales fueron extendidas irrespetuosamente, invadiendo cada rincón de la vida familiar y en especial infectando la vida privada de docentes y estudiantes, pues parece que palabras, como el ocio, la recreación y el descanso, pasaron a ser reemplazadas en tiempos de pandemia por Teams ${ }^{\circledR}$, Google Meets ${ }^{\circledR}$, Facebook ${ }^{\circledR}$, WhatsApp ${ }^{\circledR}$, entre otras plataformas digitales que pasaron a generar relaciones educativas y laborales a través de las pantallas. Esta coyuntura situacional, ha generado una sobrecarga de actividades de manera desmedida tanto en estudiantes como docentes, comprometiendo su estabilidad física, mental e incluso la familiar ${ }^{1}$. Docentes inmersos en un modelo rígido de educación burócrata donde la mayoría de las instituciones educativas no implementaron una modalidad virtual en el sentido magno de la globalidad, solo adoptaron estrategias remotas a una práctica tecnológica sin sentido alejadas de la verdadera esencia de la formación pedagógica.

Actualmente, el personal docente de los diferentes niveles educativos se encuentra ante un incremento de estrés, ansiedad y somatismo fisiológico por la desmedida carga laboral, sin mencionar el manejo de la ansiedad en el alumnado que desafía una dinámica social inesperada. En este sentido, agregar más presión al estrés generado por la crisis sanitaria y económica incrementará los problemas en la salud psicológica y física de muchos estudiantes y docentes por el confinamiento ${ }^{4}$.

En consideración con lo anterior, es importante señalar que, si antes de este hecho inédito ya existían dentro del
Es importante señalar que, si antes de este hecho inédito ya existían dentro del sistema educativo brechas de desigualdad que dividían a nuestros alumnos y docentes, ahora éstas se están incrementando durante la época, sobre todo para quienes no contaban con los dispositivos necesarios 
sistema educativo brechas de desigualdad que dividían a nuestros alumnos y docentes, ahora éstas se están incrementando durante la época, sobre todo para quienes no contaban con los dispositivos necesarios (computadores, tabletas, teléfonos inteligentes) y una adecuada conexión para continuar con su educación, tal vez por carecer de los recursos económicos o por habitar en espacios rurales donde aún no existe conectividad 5 .

Asimismo, otra situación tangible es la brecha de uso donde hay conectividad en el hogar, pero el número de dispositivos es menor comparado con el número de personas que conviven en un mismo espacio, situación que lleva a una organización y distribución del tiempo y del uso del dispositivo al interior del hogar 5 .

Y, aunque los alumnos en gran medida se han visto afectados por la situación actual, muchos docentes también se han perjudicado, pues no todos tienen la misma capacidad para proporcionar un aprendizaje digital, y además en muchos de ellos existen carencias de metodologías y de contenidos virtuales adaptados, sin mencionar el acceso a las plataformas que garanticen un buen funcionamiento. Además, es importante mencionar, que algunos docentes carecen de las competencias requeridas, o incluso de los elementos, el espacio y la tecnología necesaria en sus hogares para dar cumplimiento a sus obligaciones ${ }^{4}$; lo que ha incrementado las extensas jornadas laborales y desatención por parte del alumnado.

No obstante, aunque el salto de la educación a la virtualidad ha sido accidentado, hay que reconocer de manera positiva, que esta situación ha puesto en manifiesto que los procesos de enseñanza requieren ser reformados de manera urgente contando con el acompañamiento, la formación, la profesionalización, y reivindicando con ello la función docente actual. Para Chang y Yano ${ }^{6}$ las situaciones de la pandemia convergen en el sentido que garantizaron la continuación del aprendizaje, evitando en lo posible la interrupción de la educación, pues permitió la introducción o ampliación de las modalidades existentes de educación a distancia, proporcionó plataformas en línea y estimuló a maestros a utilizar aplicaciones, generar y difundir contenidos educativos.

En esta perspectiva, la sorpresiva realidad que hoy se vive permite reflexionar sobre cómo aprovechar esta situación para impulsar otros tipos de aprendizajes, otras herramientas de enseñanza, y otras metodologías de evaluación donde la flexibilidad y el saber oculto del currículo estén presentes en la enseñanza virtual. En este sentido, no es pensar que solo se trata de dar clases en línea, se trata de aceptar la realidad como base del aprendizaje de los alumnos; en otras palabras, vincular la realidad a la academia y a la formación. La actual pandemia al cerrar de manera repentina las instituciones educativas como espacios físicos, canceló el lado creativo, sensible, el lado social, y con ello las potencialidades liberadoras y críticas del alumnado, dejando tan solo la función reguladora básica de la educación: certificar y cerrar ciclos académicos ${ }^{7}$.

Por último, este breve escrito invita a la reflexión de las comunidades académicas para que adopten lineamientos institucionales y curriculares que la demanda social y de salud requiere, donde analicen la educación desde una dimensión humana y social, pero sobre todo que provean un sistema educativo donde no se pierda la esencia de la educación y tampoco el respeto y el reconocimiento a la labor docente. 
Conflicto de intereses: Las autoras declaran que no existen conflictos de intereses.

\section{Referencias}

1. Plá S. La pandemia en la escuela: entre la opresión y la esperanza. En: Educación y pandemia Una visión académica. Primera Edición. Ciudad de México: Universidad Nacional Autónoma de México; 2020. p. 30-9. [citado 12 de junio de 2020]. Available from: https://www.iisue.unam.mx/investigacion/textos/educacion_pandemia.pdf

2. García FJ. El sistema universitario ante la COVID-19: corto, medio y largo plazo. [Internet]. Universídad, una conversación pública sobre la universidad. 2020 [citado 13 de junio de 2020];1(1): [4 screens]. Available from: : https://bit.ly/2YPUeXU.

3. De la Cruz G. El hogar y la escuela: lógicas en tensión ante la COVID-19. En: Educación y pandemia Una visión académica. Primera Edición. Ciudad de México: Universidad Nacional Autónoma de México; 2020. p. 39-46. [citado 12 de junio de 2020]. Available from: https://www.iisue.unam.mx/investigacion/textos/educacion_pandemia.pdf

4. Rogero GJ. La ficción de educar a distancia. RASE. 2020;13(2):174-82. DOI: https://doi.org/10.7203/RASE.13.2.17126

5. Aguilar J. Continuidad pedagógica en el nivel medio superior: acciones y reacciones ante la emergencia sanitaria. En: Educación y pandemia: una visión académica. Primera Edición. Ciudad de México: Universidad Nacional Autónoma de México; 2020. p. 47-54. [citado 12 de junio de 2020]. Available from: https://www.iisue.unam.mx/investigacion/textos/educacion_pandemia.pdf

6. Chang G, Yano S. "How are countries addressing the Covid-19 challenges in education?" .UNESCO's Section of Education Policy A snapshot of policy measures [internet] 2020 Jun[ citado 23 junio de 2020].1(1); [4 screens]. Available from: https://gemreportunesco.wordpress.com/2020/03/24/how-are-countries-addressing-the-covid-19-challenges-in-education-a-snapshot-of-policy-measures/

7. Díaz A. La escuela ausente, la necesidad de replantear su significado. En: Educación y pandemia Una visión académica. Primera Edición. Ciudad de México: Universidad Nacional Autónoma de México; 2020. p. 19-30. [citado 12 de junio de 2020]. Available from: https://www.iisue.unam.mx/investigacion/textos/educacion_pandemia.pdf 